\title{
Analysis of social attitude to the new end use of recycled water for household laundry in Australia by the regression models
}

Zhuo Chen ${ }^{1}$, Huu Hao $\mathrm{Ngo}^{1 *}$, Wenshan Guo ${ }^{1}$, Xiaochang C Wang ${ }^{2}$, Clayton Miechel ${ }^{3}$, Nigel Corby $^{4}$, Andrzej Listowski ${ }^{5}$, Kelly O’ Halloran ${ }^{6}$

${ }^{1}$ Centre for Technology in Water and Wastewater, School of Civil and Environmental Engineering, University of Technology Sydney, Sydney, NSW 2007, Australia

${ }^{2}$ Key lab of Northwest Water Resource, Environment and Ecology, MOE, Xi'an University of Architecture and Technology, Xi'an, Shaanxi Province, 710055, China

${ }^{3}$ Port Macquarie-Hastings Council, PO Box 84, Port Macquarie, NSW 2444, Australia

${ }^{4}$ City West Water, 247-251 St Albans Road, Sunshine, Vic 3020, Australia

${ }^{5}$ Sydney Olympic Park Authority, 7 Figtree Drive, Sydney, NSW 2127, Australia

${ }^{6}$ Gold Coast Water, Gold Coast MC 9726, Australia

*Corresponding author, Email: h.ngo@uts.edu.au, Tel: +61 (2) 95142745, Fax: + 61(2) 95142633

\begin{abstract}
:
Recycled water for household laundry can be regarded as a promising strategy to alleviate the current demand on scarce water supplies. Public acceptability becomes fairly important to ensure the successful establishment and development of this new end use. To address the issue, this study conducted social surveys in two locations of Australia, Port Macquarie and Melbourne, where respondents were asked 17 questions. The regression models provide conclusions about which characteristics are more likely to lead to the acceptance of recycled water from society. Three attitudinal variables (RWAlterDW, Attitude and Cost) and three psychological variables (Odour, Reading and SmallUnit) were found to be the key driving forces behind domestic water reuse behaviour. These findings could drive the future research direction to achieve better public perception of this new end use of recycled water.
\end{abstract}

Keywords: Recycled water for household laundry; Social survey; Regression model 


\section{Introduction}

Faced with fast-growing population and increasing water demand as well as highly variable climate and serious precipitation imbalances, many locations in Australia have experienced water shortage problems. In the last decades, due to prolonged drought conditions, all Australian capital cities, except Darwin and Hobart, have imposed water restrictions to curtail demand and protect supplies (Ryan et al., 2009; Chen et al., 2012a). Despite recent flooding rains in eastern Australia, current water consumption practices are widely recognized to be unsustainable (Hurlimann and Dolnicar, 2012). These issues have highlighted the importance of exploiting all other possible sources of water before using up limited freshwater supplies. As a consequence, recycled water that originates from wastewater treatment is increasingly being considered as a realistic option for supplementary water supply. This can help to alleviate the pressure on existing water supplies, protect water bodies from being polluted and on the other hand provide a more constant volume of water than rainfall-dependent sources (Dolnicar and Schäfer, 2009; Chen et al., 2012b).

There are over 580 different recycled water schemes across Australia at present, which are mostly associated with non-potable uses (e.g., irrigation, industry, residential uses and environmental flows). Particularly, the households' use of recycled water continued to increase, with a 6\% growth from 3,106 ML in 2009-10 to 3,283 ML in 2010-11. However, the amount of treated effluent being reused in Australia (351 GL in 2010-11) is still low compared with the total discharged wastewater and there is considerable inconsistency in water management across local, state and territory governments (ABS, 2012). The NSW Government has set the goal to increase the water recycling rate from $9.8 \%$ in $2009-10$ to $14.7 \%$ by 2015 . While in Melbourne, Victoria, the recycling rate has already reached $22.8 \%$ 
in 2009-10. Since a number of dual pipe systems have been built in newly developed residential areas, it is anticipated that 40,000 new homes and businesses in Melbourne will use an additional amount of recycled water, which will bring the water recycling to $26.1 \%$ by 2015 (Whiteoak et al., 2012). To meet the aggressive recycling targets in the near future, many more recycled water schemes as well as new end uses should be increasingly explored and developed.

Since the household water use is the second largest user of water in Australia and approximately $20 \%$ of overall Australian household water usage is in the laundry, significant fresh water savings could be achieved if potable-quality water used for clothes washing is replaced with recycled water (Chen et al., 2012a). However, when this strategic policy is to be achieved, apart from technical concerns of producing high quality water reliably and economically, research into community attitude is of great importance. As the Australian community had very little experience on utilising recycled water for uses with relatively high personal contact, some people displayed substantial resistance against several recycling projects. For instance, in Toowoomba, the local community voted against the development of an indirect potable water recycling project in spite of critically low dam levels (Hurlimann and Dolnicar, 2010a). The initial potable water recycling plant in Quaker's Hill, north-west of Sydney, was also put aside owing to public misgiving (McClellan, 1998; Stenekes et al., 2006).

Having recognized the potential great benefits, several social studies and assessments on the use of recycled water have been carried out. Pham et al. (2011) performed research surveys on public attitudes towards recycled water in Sydney and showed that around $60 \%$ of the local respondents supported the use of recycled water for washing machine. They also 
indicated that the major concerns for public over this end use are public health, water clearness, cost and machine durability (Chen et al., 2012a). Additionally, Dolnicar et al. (2011) found that the positive environmental attitudes, positive perceptions of recycled water, the higher influence of other people, more knowledge, experience of water restrictions and watching State TV channels, increased the stated likelihood of using recycled water (Hurlimann and Dolnicar, 2010b). Nevertheless, what drives people to actively participate in recycled water for laundry use is yet to be investigated and understood in detail. Hence, the main purposes of this paper are to further identify the household laundry behaviour, knowledge and attitude about water saving and recycled water use, and the impacts as well as measures that people are concerned when implementing this new end use. A final regression relationship between these behaviours/concerns and the willingness to accept the use of recycled water in laundry was proposed. This information, together with other gathered implications, could provide sound suggestions for future research.

\section{Research methodology}

\subsection{The surveys}

The survey was conducted in two places of Australia, Port Macquarie and Melbourne over a one-month period from $9^{\text {th }}$ November to $10^{\text {th }}$ December 2012 by using questionnaire. The need for recycled water in household laundry and for other uses in these two places stems from the inequable water supply and environmental concerns and is encouraged by the city council and local water supplier. Figure 1 depicts the geographical locations of the study areas. Port Macquarie is a city on the mid north coast of New South Wales (NSW), about 390 $\mathrm{km}$ north of Sydney, with 73,000 people. Around 32\% of the population was aged 65 years 
and over in 2011, indicating a preference of older people for coastal and rural retirement. Overall, $6.9 \%$ of the population earned a high income (those earning AU \$1,500 per week or more), and $42.7 \%$ earned a low income (those earning less than $\$ 400$ per week), compared with $9.2 \%$ and $40.0 \%$ respectively for regional NSW. The median individual income was AU $\$ 25,000$ per year (ABS, 2011; PMHC, 2013). Currently, only $1.5 \mathrm{ML} /$ day of recycled water from Bonny Hills STP is used for irrigating Port Macquarie Golf club and horticultural areas. The Port Macquarie-Hastings Council (PMHC), the local government has upgraded the Dunbogan STP to serve 15,000 people in Camden Haven area since July 2010, which employs the membrane bioreactor (MBR) treatment to produce an effluent of tertiary treatment quality. The treated effluent is currently discharged to the environment directly rather than reused. To satisfy any shortfall between water supply and demand in the future, the PMHC is considering utilization of the Dunbogan STP as a future source for additional recycled water supply, which would then give a combined source capacity of 2.5 to 3.0 ML/day and up to 5.0 ML/day (PMHC, 2012). Consequently, 181 surveys were performed (151 by interview and 30 by mail) in Port Macquarie, most of which were collected in residential areas near Dunbogan STP (e.g., Laurieton and North Haven) where respondents are likely to be potential customers of recycled water in the near future.

With respect to Melbourne, Victoria, there were an estimated 4.17 million people in 2011 and only $13 \%$ of the population was aged 65 years and over. The average annual income in 200809 was $\mathrm{AU} \$ 47,000$ with more than $18 \%$ of the population earning a high income and $23.1 \%$ having a low income (ABS, 2011). The Western Treatment Plant has been supplying 37 GL/year of recycled water for agriculture and landscape irrigation (e.g., golf club, parks, zoos and wetlands) in Werribee area, a suburb around $32 \mathrm{~km}$ southwest of Melbourne's CBD. In the City of Wyndham Vale, Werribee, the dual pipe recycled water systems have already 
been installed in front/back yard of 2,000 new homes which will be receiving Class A recycled water in December 2013 through the purple pipe. Hence, 152 surveys were conducted (by interview) in Werribee area, most of which were collected in Wyndham Vale where dual pipe systems have been constructed and recycled water will soon be supplied to new homes (City West Water, 2012). The respondents were assuring of anonymity. Specifically, to carry out the face-to-face interview, researchers performed door-to-door knocks or stayed at some of the busiest local points (e.g., shopping centres, parks, swimming pools and stations) and randomly selected pedestrians at different hours of the day in the morning and in the afternoon, on a first-to-pass basis (Menegaki et al., 2007).

\section{Fig. 1.}

\subsection{Model structure}

The impacts of household laundry behaviour and community attitude on the acceptance of recycled water in laundry were initially measured by chi-square test, using software MATLAB R2012b as the analysis tool. Since chi-square test could only tell whether the two variables are associated with each other rather than figuring out the depth of relationship, regression models were further employed to identify the linear relationship between predictor variables (e.g., behavioural, attitudinal and psychological variables) and response variable (likelihood of using recycled water in laundry). The regression analyses were performed by the software SPSS (Statistical Package for the Social Sciences) package. The basic form of regression function is:

$\operatorname{logit}(\pi)=\ln \left(\frac{\pi}{1-\pi}\right)=\alpha+\beta_{1} X_{1}+\beta_{2} X_{2}+\ldots+\beta_{\mathrm{p}} X_{p}$ 
where, $\pi$ represents the probability of being supportive to recycled water use in laundry; $\alpha$ is the intercept parameter, and $\beta$ is the coefficient associated with the $\mathrm{j}^{\text {th }}$ predictor variable, $\mathrm{X}_{\mathrm{j}}$ (Azen and Walker, 2011; Tutz, 2012). Particularly, the constant term $(\alpha)$ is the estimated log odds of being supportive on recycled water use in laundry with whole observations, holding all predictor variables at the reference categories. The negative estimates $(\beta)$ indicate that an increase in the variable (e.g., the higher the perceived cost) leads to a decrease in acceptance. The regression models also give additional information on the standard error and odds ratio. The standard error indicates the precision of the coefficient and the $95 \%$ confidence interval for the coefficient is approximately given by: Coefficient \pm 2 Standard Error (Dolnicar et al., 2011), while the odds ratio column provides the information about how sensitive the response variable is to each of the factors.

The respondents were asked questions regarding their opinions, attitudes, knowledge and concerns on water scarcity issues as well as receiving recycled water at home. These items were answered on numerical rating scales (Table 1). To simplify the calculation of statistical analysis, predictor variables, except the cost variable, were recoded into 2-point scale. Positive responses were classified into Category 1 (0) while negative and Unsure/ don't know responses were included in Category 2 (1). Category 2 was regarded as the reference category. The perceived cost was proved to play an important role in satisfaction of recycled water use (Hurlimann et al., 2008). Thus, cost variable in this study was examined in greater detail and recoded into 3-point scale: responses 1-2, 3, 4-5 were included in Category 1 (0), Category 2 (1) or Category 3 (2) respectively. In this case, Category 3 was regarded as the reference category. Respondents also had the option not to answer a question, which was then marked as Not Applicable (0). As the number of Not Applicable answers in the survey was small except the first four psychological variables listed in Table 1, they were classified into 
Unsure/ don't know responses. However, the average of Not Applicable answers for psychological variables (Colour, Clothes, Washing Machine and Odour) was 7.5\% which could not be neglected. In this case, respondents who had chosen Not Applicable answer in any of these four variables were removed because their correlations with the model regressors were insignificant, leading to an exclusion of $10.8 \%$ of the respondents.

\section{Table 1}

\section{Results and discussion}

\subsection{Regression Model 1 and Model 2}

This survey did not address the socio-demographic variables (e.g., gender, age, income and education) as their effects on the public acceptance of recycled water has already been analysed by other papers (Dolničar and Saunders, 2005; Menegaki et al., 2007). Some research showed that people with a higher level of income and education exhibited more willingness to adopt recycled water (Tsagarakis and Georganzís, 2003), while others found socio-demographic factors are not good predictors on recycled water acceptance (Marks, 2004; Hurlimann et al., 2008). Although respondents in two survey locations demonstrated slightly different household laundry behaviour (e.g., choice of washing detergent) due to distinct family size, age composition and living habits, their attitude and knowledge on water related issues exhibited no significant differences. According to chi-square tests in Table 1, three attitudinal variables and six psychological variables were proved to have a relationship with the final acceptance of recycled water use in laundry $(p<0.05)$. Therefore, these variables have been selected as predictor variables in Model 1 and 2 (Table 2). In Model 1, 
all predictor variables were regarded as independent to each other so that the interactions between different variables did not take into account. In contrast, Model 2 added all pairwise interactions between the variables in the model.

\section{Table 2}

Table 2 gives the corresponding model coefficient estimates together with the standard errors and odds ratios. The order of estimates is in the sequence each entered the model. When the predictor variable is increased by one unit, the response variable will increase with the estimated unit (Dolnicar et al., 2011). For example, in Model 1, given other predictor variables at reference categories, a one unit increase in attitude variable changes the odds of the acceptance on recycled water use in laundry multiplicatively by a factor of 4.067. It is worth to notice that compared with Model 1, all parameters in Model 2 changed slightly when adding the interaction terms, showing that the combined effect of predictor variables is different from their separate effects. Particularly, the estimated values of coefficients for colour and clothes variables were changed from positive to negative, indicating that the community would be less concerned about these psychological issues when giving a series of questions together than facing separate issues. Besides, it can be observed that in Model 2, when considering the combined effect of two variables on the acceptance level, the interaction effect seems to partially offset the simple additive effect posed by independent variables. For instance, although the two variables, positive attitude and the greater confidence by reading from other customers, separately have a positive effect on increasing the community acceptance, their combined effect was reduced if the interaction effect is taken into account (2.731 rather than 4.103). 
The following variables were significant at the 0.05 level: in Model 1, RWAlterDW, Attitude, Odour and SmallUnit; in Model 2, RWAlterDW, Attitude, Cost, Odour, Reading, SmallUnit, Reading by SmallUnit, Attitude by Reading, and Colour by Odour. They are the main aspects to change the level of acceptance that respondents would use recycled water in laundry. With respect to the usefulness of the model, both Model 1 and 2 could predict over $80 \%$ of the observations correctly. The higher the overall percentage of correct predictions, the better the model is. Another approach to access the effectiveness of the model is the Negelkerke $\mathrm{R}^{2}$ test, which gives the proportion of variation in the outcome variable being explained by the model. A small $\mathrm{R}^{2}$ value means that the model is not a great improvement over the null model with no predictors. As Model 1 and 2 could explain about 41.4 and $45.8 \%$ of the variation in data respectively, they were capable of accounting for a substantial amount of the variance. Moreover, Hosmer and Lemeshow test was also performed, which is to form groups of cases and construct a "goodness-of-fit" statistic by comparing the observed and predicted number of events in each group (Azen and Walker, 2011). When the p-value in Hosmer and Lemeshow test is greater than 0.05 , there is no significant difference between observed and model-predicted values, implying that the model's estimates fit the data at an acceptable level. Both Model 1 and 2 appear to fit the data reasonably well. Overall, the model that includes interaction terms (Model 2) is better at predicting the observed data associated with recycled water use in laundry than the Model with just independent variables (Model 1).

\subsection{Regression Model 3}

Nevertheless, as the Model 2 involves nine predictor variables along with six different interaction effects between variables, the interpretation of model parameters is somewhat complicated. For ease of understanding, only six variables in Model 2 which were found to 
have a significant relationship with tendency to use recycled water in laundry were included in the Model 3. Based on goodness-of-fit tests, Model 3 fits the data well. It can be written as:

$\operatorname{logit}(\pi)=-2.274+1.901 R W A$ AlerDW $(0)+2.216$ Attitude $(0)-0.261 \operatorname{Cost}(0)$

-0.414 Cost $(1)-1.685$ Odour $(0)+1.884$ Reading $(0)+1.428$ SmallUnit $(0)$

-1.045Reading.SmallUnit-1.256Attitude.Reading

As can be seen from Table 2 and Figure 2, the effect is strongest for those who exhibited positive attitude on receiving recycled water, followed by respondents recognising recycled water as an alternative to drinking water. Each additional score on Attitude and RWAlterDW scale increase the chance of accepting recycled water use in laundry more than 6 times. Moreover, enhancing the respondent confidence by introduction of successful examples and/or installation of a small unit for pre-treatment is also able to greatly improve the acceptance level of recycled water use in laundry. However, the interpretation of the relation between increased confidence by reading from others and the final acceptance also requires the consideration of two-way interactions since the interactions with adding a small unit and presenting positive attitude weakened the direct simple effect posed by a single reading factor. Remarkably, odour and perceived cost are also key influential factors, and they showed negative impacts on the acceptance. This anxiety may be closely related to respondents' inherent thoughts on recycled water as the origin of recycled water is the odorous wastewater and the cost for wastewater treatment is relatively high owing to the complexity of pollutants.

\section{Fig. 2.}

The findings from regression models have important practical implications as there are very few researches addressing the influences of attitudinal and psychological factors on the 
community satisfaction of recycled water in laundry. Although the major public concerns on recycled water uses can be drawn from previous research surveys, the important drivers that promote the public involvement in new strategies of the scheme are still ambiguous. However, this study provides guidance to water providers and government policy makers about interventions that are likely to increase public acceptance of recycled water on new applications with high personal contact. Specifically, it is advisable to offer more education campaigns to let the public understand the current water shortage status and the importance/advantage of recycled water as an alterative water resource. People's positive attitude on recycled water can also be established through relevant information or updates provided by brochures via mail, websites or email and articles on newspapers which are proved to be preferred ways for the community to receive additional information. Besides, apart from a better water quality control program, to reassure the community, particularly regarding the potential odour and perceived high cost issues, it is feasible to encourage personal communications, especially with people who have previous experiences on water reuse. Launching workshops, which allows people to be able to watch treatment processes and experience recycled water, may be another useful strategies. These approaches are likely to be far more effective than blunt public announcements stating that recycled water would be added to dual pipe system to households (Dolnicar et al., 2011).

Nevertheless, as this study was conducted in two places of Australia only, the developed regression models of satisfaction of recycled water use in laundry seem to be plausible but may not be accurate or true across the whole country. Future research on refinement of the model include: consideration of additional predictor variables, such as risk perceptions, environmental concerns, information search and TV watching behaviour, etc.; and reduction of regional effects by conducting more case studies. Still, the model does provide insight that 
attitudinal and psychological factors have strong relationships with the acceptance level of new end uses of recycled water. This could be beneficial to other recycled water providers, water authorities and policy maker involving the expansion of recycled water supply.

\section{Conclusion}

Public acceptability is a prerequisite for society to establish and promote new recycled water end uses. Presently, little achievement has been made on public acquiescence towards this matter in Australia. Through extensive social attitude surveys in Port Macquarie, NSW and Melbourne, Victoria, this study constructs regression relationships between predicting variables and the public acceptance on recycled water use in laundry. The variables significantly contributing to the acceptance of this new end use were: (i) positive attitude on receiving recycled water, (ii) positive opinion on the idea "recycled water is an alternative to drinking water", (iii) increased confidence by reading from other customers or successful examples, and (iv) increased confidence by adding a small unit to improve the water quality.

The fear of the potential odour and high cost when using recycled water for household laundry are the main factors to prevent respondents from being supportive to this new end use. These findings reconfirm that building community's knowledge, trust and confidence on water saving and current recycled water status are the critical points in ensuring the smooth expansion of recycled water supply or introduction of new applications. While the increment of public acceptability is a long-term participatory procedure, some corresponding policy strategies should be primarily taken to guarantee the implementation in a cost-effective way. The methodology and suggestions from this paper could be further applied in other locations within or outside Australia to obtain holistic community views. 


\section{Acknowledgement}

This work was funded by Australian Research Council (ARC) Industry Linkage Grant (LP100100494).

\section{References}

ABS, 2011. Australian Bureau of Statistics. Population by Age and Sex, Regions of Australia, 2011. http://www.abs.gov.au/Ausstats/abs@.nsf/mf/3235.0.

ABS, 2012. Australian Bureau of Statistics. Water Account Australia 2010-11. http:// www.abs.gov.au/AUSSTATS/abs@.nsf/DetailsPage/4610.02010-11?Open Document.

Azen, R., Walker, C.M., 2011. Categorical data analysis for the behavioural and social sciences. Taylor \& Francis Group, New York.

Chen, Z., Ngo, H.H., Guo, W.S., Listowski, A., O'Halloran, K., Thompson, M., Muthukaruppan, M., 2012a. Multi-criteria analysis towards the new end use of recycled water for household laundry: A case study in Sydney. Sci. Total Environ. 438, 59-65.

Chen, Z., Ngo, H.H., Guo, W.S., Wang, X.C., 2012b. Analysis of Sydney's recycled water schemes. Front Environ Sci Eng. in press.

City West Water, 2012. Alternative water supplies. http://www.citywestwater.com.au/ residents/alternative_water_supplies.aspx.

Dolničar, S., Saunders, C., 2005. Marketing recycled water: review of past studies and research agenda, in: Khan, S.J., Schafer, A.I., Muston, M.H. (Eds.), Integrated Concepts in Water Recycling. University of Wollongong, Wollongong, pp. 181-192.

Dolnicar, S., Schäfer, A.I., 2009. Desalinated versus recycled water: public perceptions and profiles of the accepters. J. Environ. Manage. 90, 888-900. 
Dolnicar, S., Hurlimann, A., Grün, B., 2011. What affects public acceptance of recycled and desalinated water? Water Res. 45, 933-943.

Google Map, 2013. http://maps.google.com.

Hurlimann, A., Dolnicar, S., 2010a. When public opposition defeats alternative water projects - The case of Toowoomba Australia. Water Res. 44, 287-297.

Hurlimann, A., Dolnicar, S., 2010b. Acceptance of water alternatives in Australia-2009. Water Sci. Technol. 61, 2137-2142.

Hurlimann, A., Dolnicar, S., 2012. Newspaper coverage of water issues in Australia. Water Res. 46, 6497-6507.

Hurlimann, A., Hemphill, E., McKay, J., Geursen, G., 2008. Establishing components of community satisfaction with recycled water use through a structural equation model. J. Environ. Manage. 88, 1221-1232.

Marks, J., 2004. Advancing community acceptance of reclaimed water. Water J. Au. Water Assoc. 31, 46-51.

McClellan, P., 1998. Sydney water inquiry (final report): Introduction, recommendations and actions. Sydney: Premier's Department, New South Wales Government.

Menegaki, A.N., Hanley, N., Tsagarakis, K.P., 2007. The social acceptability and valuation of recycled water in Crete: A study of consumer's and farmer's attitudes. Ecol. Econ. 62, $7-18$.

Pham, T.T.N., Ngo, H.H., Guo, W.S., Dang, H.P.D., Mainali, B., Johnston, A., Listowski, A., 2011. Response of community to the public use of recycled water for washing machine: a case study in Sydney, Australia. Resour Conserv Recycl. 55, 535-540.

PMHC, 2012. Port Macquarie-Hastings Council. Waste water management. http://www. hastings.nsw.gov.au/www/html/3449-the-process.asp. 
PMHC, 2013. Port Macquarie-Hastings Council. Community profile. http://profile.id.com. au/hastings.

Ryan, A.M., Spash, C.L., Measham, T.G., 2009. Socio-economic and psychological predictors of domestic greywater and rainwater collection: Evidence from Australia. J. Hydrol. 379, 164-171.

Stenekes, N., Colebatch, H.K., Waite, T.D., Ashbolt, N.J., 2006. Risk and governance in water recycling: public acceptance revisited. Sci. Technol. Hum. Val. 31, 107-134.

The Lost Seed, 2013. Retail Stockists. http://www.thelostseed.com.au/retail-stockists/ \#.UUv7gxf-KeZ.

Tsagarakis, K.P., Georganzís, N., 2003. The role of information on farmer's willingness to use recycled water for irrigation. Water Sci. Technol. 3, 105-113.

Tutz, G., 2012. Regression for categorical data. Cambridge University Press, New York.

Whiteoak, K., Jones, P., Pickering, P., 2012. Progress against the national target of $30 \%$ of Australia's wastewater being recycled by 2015. http://www.environment.gov.au/water/ publications/urban/pubs/recycled-water-target-final-report.pdf. 
Table 1

Factors found to influence community acceptance of recycled water in laundry

\begin{tabular}{|c|c|c|c|c|c|c|}
\hline Variable & Rating & $\begin{array}{l}\text { Support } \\
(\%)\end{array}$ & $\begin{array}{l}\text { Uncertain } \\
(\%)\end{array}$ & $\begin{array}{l}\text { Against } \\
(\%)\end{array}$ & $\chi^{2}$ & $\mathrm{p}$ \\
\hline \multicolumn{7}{|l|}{ Attitudinal variables } \\
\hline \multirow{4}{*}{$\begin{array}{l}\text { Recycled water is an } \\
\text { alternative to drinking } \\
\text { water }\end{array}$} & Strongly agree & 25.23 & 3.30 & 1.20 & \multirow[t]{4}{*}{96.71} & \multirow[t]{4}{*}{0.0000} \\
\hline & Agree & 40.84 & 15.02 & 3.30 & & \\
\hline & Disagree & 1.50 & 5.11 & 0.60 & & \\
\hline & Strongly disagree & 0.30 & 1.20 & 0.90 & & \\
\hline \multirow{5}{*}{$\begin{array}{l}\text { Attitude on receiving } \\
\text { recycled water }\end{array}$} & Very happy & 22.52 & 3.00 & 1.20 & \multirow[t]{5}{*}{109.3} & \multirow[t]{5}{*}{0.0000} \\
\hline & Happy & 36.94 & 9.01 & 1.80 & & \\
\hline & Unsure & 8.41 & 9.31 & 2.10 & & \\
\hline & Not happy & 0.30 & 2.70 & 0.30 & & \\
\hline & Very unhappy & 0.00 & 0.30 & 0.90 & & \\
\hline \multirow{5}{*}{$\begin{array}{l}\text { The cost of recycled } \\
\text { water compared to } \\
\text { drinking water }\end{array}$} & Much higher & 1.80 & 2.10 & 0.60 & \multirow[t]{5}{*}{33.78} & \multirow[t]{5}{*}{0.0037} \\
\hline & Higher & 12.01 & 5.11 & 2.10 & & \\
\hline & The same & 12.31 & 4.50 & 0.60 & & \\
\hline & Slightly lower & 22.52 & 5.71 & 0.90 & & \\
\hline & Much lower & 15.02 & 4.80 & 1.50 & & \\
\hline \multicolumn{7}{|c|}{ Psychological variables } \\
\hline \multirow{3}{*}{$\begin{array}{l}\text { Be concerned of colour } \\
\text { of clothes }\end{array}$} & Yes & 32.43 & 14.41 & 3.60 & \multirow[t]{3}{*}{10.85} & \multirow[t]{3}{*}{0.0283} \\
\hline & No & 25.23 & 5.11 & 1.20 & & \\
\hline & Unsure & 5.71 & 3.30 & 1.20 & & \\
\hline \multirow{3}{*}{$\begin{array}{l}\text { Be concerned of } \\
\text { damage to clothes }\end{array}$} & Yes & 29.73 & 12.91 & 3.90 & \multirow[t]{3}{*}{14.31} & \multirow[t]{3}{*}{0.0064} \\
\hline & No & 28.83 & 6.31 & 0.90 & & \\
\hline & Unsure & 4.50 & 3.00 & 1.20 & & \\
\hline \multirow{3}{*}{$\begin{array}{l}\text { Be concerned of } \\
\text { damage to washing } \\
\text { machine }\end{array}$} & Yes & 25.83 & 13.21 & 3.90 & \multirow[t]{3}{*}{17.89} & \multirow[t]{3}{*}{0.0013} \\
\hline & No & 30.63 & 5.41 & 1.20 & & \\
\hline & Unsure & 6.01 & 3.60 & 0.90 & & \\
\hline \multirow{3}{*}{$\begin{array}{l}\text { Be concerned of odour } \\
\text { caused by recycled } \\
\text { water }\end{array}$} & Yes & 31.83 & 17.72 & 5.11 & \multirow[t]{3}{*}{36.22} & \multirow[t]{3}{*}{0.0000} \\
\hline & No & 25.83 & 2.10 & 0.00 & & \\
\hline & Unsure & 5.71 & 2.40 & 1.20 & & \\
\hline \multirow{3}{*}{$\begin{array}{l}\text { Confidence increased } \\
\text { by reading recycled } \\
\text { water being used by } \\
\text { other people }\end{array}$} & Yes & 48.65 & 13.21 & 2.10 & \multirow[t]{3}{*}{47.83} & \multirow[t]{3}{*}{0.0000} \\
\hline & No & 9.61 & 3.90 & 3.90 & & \\
\hline & Unsure & 3.30 & 4.80 & 0.00 & & \\
\hline \multirow{3}{*}{$\begin{array}{l}\text { Confidence increased } \\
\text { by having a small unit } \\
\text { for pre-treatment }\end{array}$} & Yes & 52.25 & 13.21 & 2.40 & \multirow[t]{3}{*}{42.03} & 0.0000 \\
\hline & No & 6.31 & 3.90 & 3.00 & & \\
\hline & Unsure & 3.60 & 4.80 & 0.60 & & \\
\hline
\end{tabular}


Table 2

Logistic regression for recycled water

\begin{tabular}{|c|c|c|c|c|c|c|c|c|c|}
\hline \multirow{3}{*}{ Predictor variables } & \multicolumn{9}{|c|}{ Regression Models } \\
\hline & \multicolumn{3}{|c|}{ Model 1} & \multicolumn{3}{|c|}{ Model 2} & \multicolumn{3}{|c|}{ Model 3} \\
\hline & $\mathrm{COEF}$ & $\mathrm{SE}$ & OR & $\mathrm{COEF}$ & $\mathrm{SE}$ & OR & $\mathrm{COEF}$ & $\mathrm{SE}$ & OR \\
\hline Constant & $-1.465^{*}$ & 0.503 & 0.231 & $-1.885^{*}$ & 0.745 & 0.152 & $-2.274^{*}$ & 0.586 & 0.103 \\
\hline RWAlterDW (positive) & $1.916 *$ & 0.465 & 6.792 & $2.039 *$ & 0.646 & 7.684 & $1.901 *$ & 0.470 & 6.692 \\
\hline Attitude (positive) & $1.403 *$ & 0.312 & 4.067 & $2.095 *$ & 1.055 & 8.122 & $2.216^{*}$ & 0.447 & 9.171 \\
\hline Cost (higher) & -0.308 & 0.309 & 0.735 & -0.480 & 0.328 & 0.619 & -0.261 & 0.306 & 0.770 \\
\hline Cost (the same) & -0.607 & 0.332 & 0.545 & $-0.829 *$ & 0.354 & 0.436 & -0.414 & 0.319 & 0.661 \\
\hline Colour (concerned) & 0.484 & 0.362 & 1.622 & -1.042 & 0.689 & 0.353 & - & - & - \\
\hline Clothes (concerned) & 0.140 & 0.380 & 1.150 & -0.095 & 0.570 & 0.910 & - & - & - \\
\hline Machine (concerned) & -0.240 & 0.310 & 0.787 & -0.990 & 0.663 & 0.372 & - & - & - \\
\hline Odour (concerned) & $-2.077 *$ & 0.372 & 0.125 & $-2.960^{*}$ & 0.493 & 0.052 & $-1.685^{*}$ & 0.285 & 0.186 \\
\hline Reading (effective) & 0.278 & 0.289 & 1.320 & $2.008 *$ & 0.655 & 7.445 & $1.884^{*}$ & 0.598 & 6.581 \\
\hline SmallUnit (effective) & $0.990 *$ & 0.288 & 2.692 & $1.942 *$ & 0.485 & 6.971 & $1.428 *$ & 0.435 & 4.169 \\
\hline \multicolumn{10}{|l|}{ Interactions } \\
\hline Reading by SmallUnit & - & - & - & $-1.334^{*}$ & 0.633 & 0.263 & -1.045 & 0.590 & 0.352 \\
\hline Attitude by Reading & - & - & - & $-1.372 *$ & 0.662 & 0.254 & $-1.256^{*}$ & 0.591 & 0.285 \\
\hline Colour by Odour & - & - & - & $1.495 *$ & 0.721 & 4.457 & - & - & - \\
\hline Machine by Odour & - & - & - & 1.071 & 0.725 & 2.918 & - & - & - \\
\hline Attitude by RWAlterDW & - & - & - & -0.009 & 0.990 & 0.991 & - & - & - \\
\hline Colour by Clothes & - & - & - & 0.591 & 0.735 & 1.806 & - & - & - \\
\hline \multicolumn{10}{|l|}{ Goodness-of-fit } \\
\hline Overall percentage correct $(\%)$ & \multicolumn{3}{|c|}{80.5} & \multicolumn{3}{|c|}{81.1} & \multicolumn{3}{|c|}{80.8} \\
\hline Negelkerke $\mathrm{R}^{2}$ & \multicolumn{3}{|c|}{0.414} & \multicolumn{3}{|c|}{0.458} & \multicolumn{3}{|c|}{0.422} \\
\hline Hosmer and Lemeshow & \multicolumn{3}{|c|}{$\chi^{2}: 12.827 ; \mathrm{p}$-value: 0.076} & \multicolumn{3}{|c|}{$\chi^{2}: 11.520 ; \mathrm{p}$-value: 0.118} & \multicolumn{3}{|c|}{$\chi^{2}: 8.203 ; \mathrm{p}$-value: 0.224} \\
\hline
\end{tabular}

Abbreviations: $\mathrm{COEF}=$ Coefficient; $\mathrm{SE}=$ Standard Error; $\mathrm{OR}=$ Odds Ratio; RWAlterDW= Recycled water is an alternative to drinking water

*Asterisks indicate significant at the 0.05 level. 


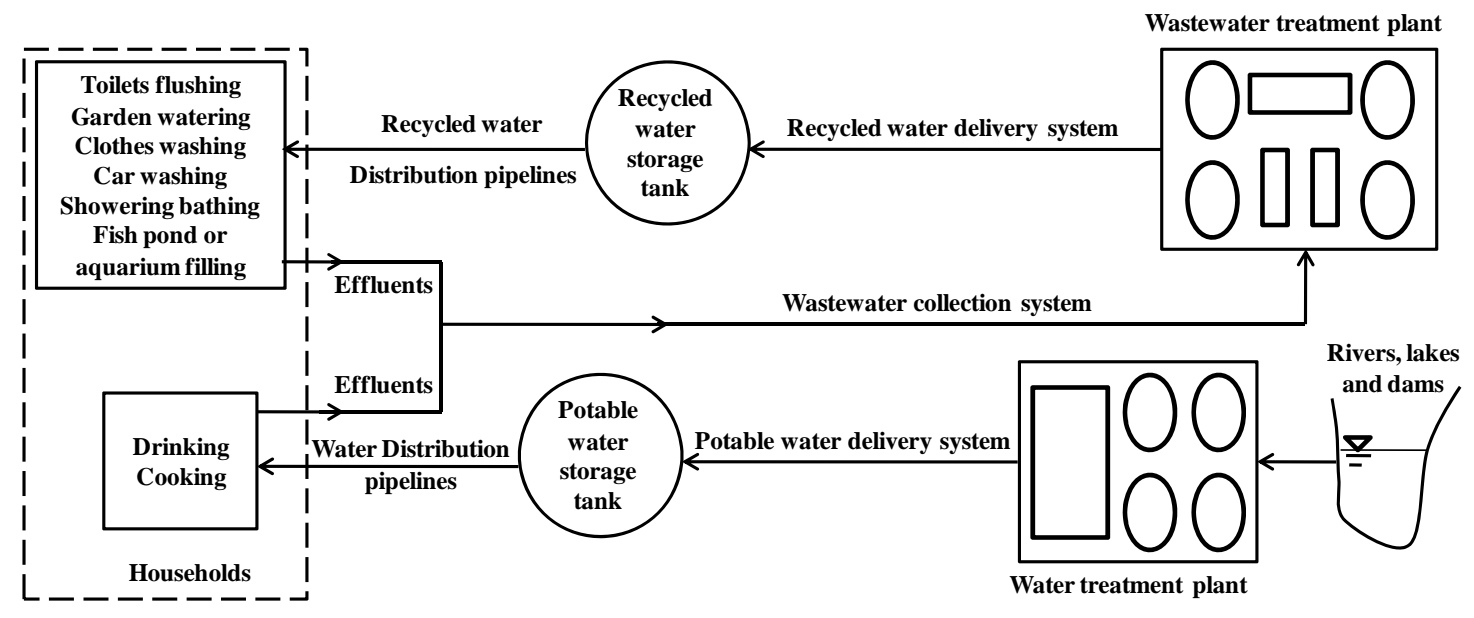

Fig. 1. Sketch map of dual pipe recycled water system in Wyndham Vale, Melbourne

(Modified from Chen et al., 2012c) 


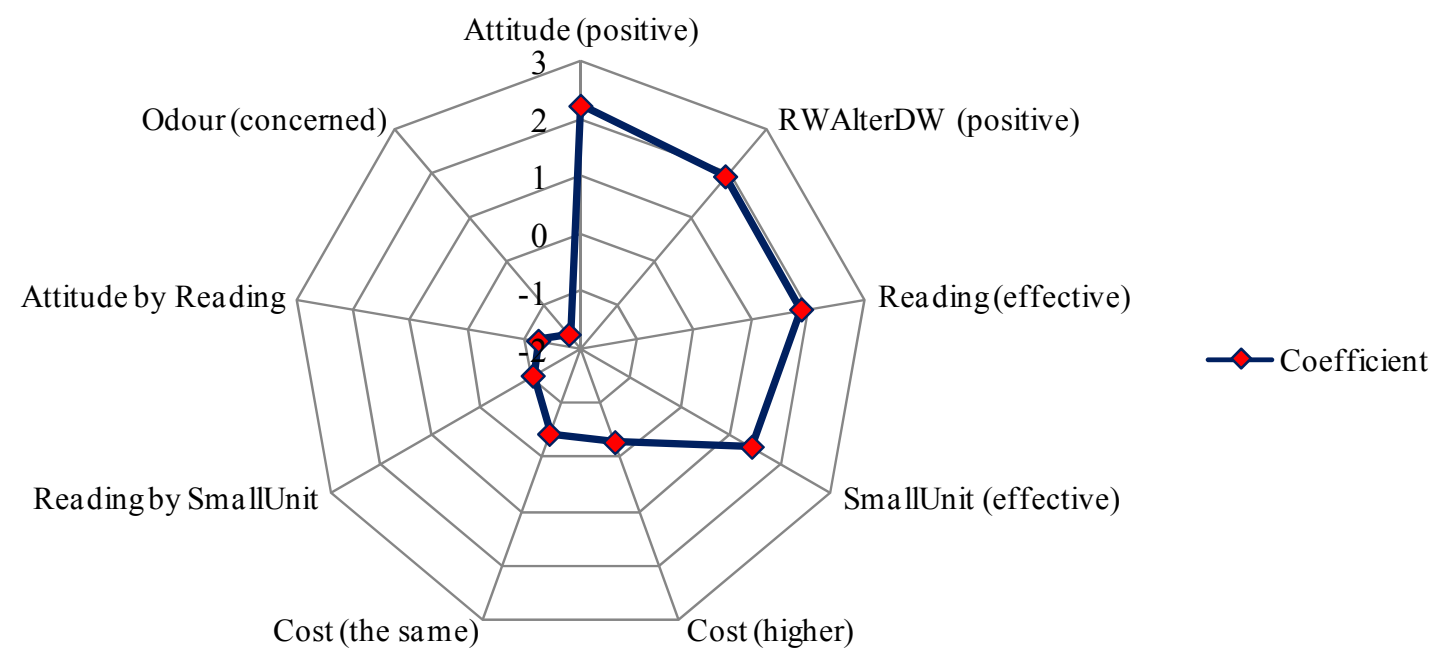

Fig. 2. Extent of the variable effect in Model 3 on final acceptance of recycled water 